\title{
CORRIGENDUM
}

\section{The effects of an anabolic agent on body composition and pulmonary function in tetraplegia: a pilot study}

LS Halstead, SL Groah, A Libin, LF Hamm and L Priestley

Spinal Cord (2010) 48, 180; doi:10.1038/sc.2009.129

Correction to: Spinal Cord advance online publication, 7 July 2009; doi:10.1038/sc.2009.82

Since the publication of the above article, the authors have noticed that the first sentence in the Design section has omitted the source of medication. The correct sentence is shown below:
This was a prospective repeated-measures pilot study of 10 subjects who took $20 \mathrm{mg}$ oxandrolone (Savient Pharmaceuticals, Inc., East Brunswick, NJ, USA) orally every day in divided doses for 8 weeks.

The authors would like to apologize for this error. 